\title{
BMJ Open Effectiveness of a cough management algorithm at the transitional phase from acute to chronic cough in Australian children aged $<15$ years: protocol for a randomised controlled trial
}

\author{
Kerry-Ann F O'Grady, ${ }^{1}$ Keith Grimwood, ${ }^{2}$ Maree Toombs, ${ }^{3,4,5}$ Theo P Sloots, ${ }^{6,7}$ \\ Michael Otim, ${ }^{8}$ David Whiley, ${ }^{7}$ Jennie Anderson, ${ }^{9}$ Sheree Rablin, ${ }^{1}$ Paul J Torzillo, ${ }^{10}$ \\ Helen Buntain, ${ }^{11}$ Anne Connor, ${ }^{12}$ Don Adsett, ${ }^{13}$ Oon Meng kar, ${ }^{13}$ \\ Anne B Chang ${ }^{1,5,14}$
}

To cite: O'Grady KF, Grimwood K, Toombs M, et al. Effectiveness of a cough management algorithm at the transitional phase from acute to chronic cough in Australian children aged $<15$ years: protocol for a randomised controlled trial. BMJ Open 2017;7:e013796. doi:10.1136/bmjopen-2016013796

- Prepublication history for this paper is available online. To view these files please visit the journal online (http://dx.doi.org/10.1136/ bmjopen-2016-013796)

Received 9 August 2016 Revised 2 November 2016 Accepted 30 January 2017

CrossMark

For numbered affiliations see end of article.

Correspondence to Dr Kerry-Ann F O'Grady; kerryann.ogrady@qut.edu.au

\section{ABSTRACT}

Introduction: Acute respiratory infections (ARIs) are leading causes of hospitalisation in Australian children and, if recurrent, are associated with increased risk of chronic pulmonary disorders later in life. Chronic ( $>4$ weeks) cough in children following ARI is associated with decreased quality-of-life scores and increased health and societal economic costs. We will determine whether a validated evidence-based cough algorithm, initiated when chronic cough is first diagnosed after presentation with ARI, improves clinical outcomes in children compared with usual care.

Methods and analysis: A multicentre, parallel group, open-label, randomised controlled trial, nested within a prospective cohort study in Southeast Queensland, Australia, is underway. 750 children aged $<15$ years will be enrolled and followed weekly for 8 weeks after presenting with an ARI with cough. 214 children from this cohort with persistent cough at day 28 will be randomised to either early initiation of a cough management algorithm or usual care (107 per group). Randomisation is stratified by reason for presentation, site and total cough duration at day 28 ( $<6$ and $\geq 6$ weeks). Demographic details, risk factors, clinical histories, examination findings, cost-ofillness data, an anterior nasal swab and parent and child exhaled carbon monoxide levels (when age appropriate) are collected at enrolment. Weekly contacts will collect cough status and cost-of-illness data. Additional nasal swabs are collected at days 28 and 56 . The primary outcome is time-to-cough resolution. Secondary outcomes include direct and indirect costs of illness and the predictors of chronic cough postpresentation.

Ethics and dissemination: The Children's Health Queensland (HREC/15/QRCH/15) and the Queensland University of Technology University (1500000132) Research Ethics Committees have approved the study. The study will inform best-practice management of cough in children.

\section{Strengths and limitations of this study}

- Our study will be the first to assess the clinical and economic impact of an early, evidencebased intervention in the transitional stage from acute to chronic cough in children.

- Conducting the study in primary care facilities addresses the predominant setting in which acute respiratory illnesses are managed.

- A limitation of the study is its generalisability to children with acute respiratory illnesses in rural and remote regions.

Trial registration number: ACTRN12615000132549.

\section{INTRODUCTION}

Cough in children is one of the most common reasons for medical encounters in Australia $^{1}$ and internationally. ${ }^{2}$ In the UK, $30 \%$ of hospital paediatric medical encounters (including emergency department (ED) visits) are due to respiratory illnesses, with cough as a symptom accounting for over $8 \%$ of all presentations. ${ }^{3}$ Cough in children is present in a broad range of respiratory illnesses ranging from mild, self-limiting rhinitis to life-threatening acute and chronic pulmonary disorders. ${ }^{4}$ Furthermore, acute illness may bring to medical attention for the first time those with chronic underlying disease. In the analyses of our recent cohort study of 817 children (96\% non-Indigenous) aged $<15$ years presenting with cough to a 
tertiary paediatric ED, ${ }^{5} 20 \%$ (95\% CI 17.2 to 22.7 ) developed chronic ( $>4$ weeks duration) cough after an acute respiratory infection (ARI). Of those, $42 \%$ were diagnosed at specialist review with protracted bacterial bronchitis (PBB) and $32 \%$ were found to have a previously undiagnosed respiratory disorder, including asthma, large airway lesions (such as tracheomalacia), obstructive sleep apnoea and bronchiectasis (unpublished).

Chronic cough in children is an under-recognised, but important cause of morbidity and decreased quality of life (QoL). ${ }^{6}$ Although an economic evaluation has never been undertaken, chronic cough likely accounts for substantial direct and indirect economic costs. ${ }^{7}$ An Australian study found that $>80 \%$ of parents had sought five or more medical consultations for their child in the 12 months immediately prior to referral to respiratory specialists for their child's chronic cough. ${ }^{7}$ Nevertheless, there are few high-quality studies that address the natural history of acute and chronic cough and none completed that have a predominant focus on Australian Indigenous children. Systematic reviews of the natural history of acute cough in children in primary healthcare found wide variation in the design and quality of studies. ${ }^{8}{ }^{9}$ There was large variability in the duration of illnesses evaluated, how outcomes were measured and completeness of follow-up. Importantly, in most studies addressing acute cough in children, validated outcome measures for cough were not used; those with prolonged cough were not reviewed and there was no differentiation between 'wet' and 'dry' types. ${ }^{9}$ Wet cough is important as it implies increased airway secretions and usually indicates clinically significant lower airway infection and neutrophilic inflammation. ${ }^{10}{ }^{11}$ For example, chronic wet cough is the most common symptom of bronchiectasis $^{12}$ and early diagnosis and treatment improves long-term outcomes. ${ }^{13} 14$

Indigenous people are at high risk of developing chronic pulmonary disorders. Indeed, in nationwide data for Indigenous Australians, respiratory disorders are: (1) the most common reason for primary healthcare encounters; (2) the second most prevalent selfreported chronic condition and (3) the second most common cause for hospitalisation. ${ }^{15}$ Overall, $27 \%$ of Indigenous people report some form of respiratory disease; $19 \%$ in those aged <14 years and $38 \%$ in those aged $>55$ years. In remote Indigenous children, the rates of hospitalisation for ARI and radiographically diagnosed pneumonia, ${ }^{16} 17$ and the incidence of bronchiectasis, ${ }^{18}$ are among the highest reported worldwide. Recurrent ARI episodes are common ${ }^{17}$ and studies in Indigenous children from central and northern Australia demonstrated associations between these infections and subsequent diagnosis of bronchiectasis. ${ }^{19} 20$

To date, the focus on ARI has been largely on remote Indigenous children, with limited community-based data from those living in urban settings. This is despite socioeconomic and health indices being consistently lower for urban Indigenous populations compared with
non-Indigenous groups. ${ }^{15}$ The lack of data on urban and rural Indigenous populations has been identified as a significant barrier to 'Closing the Gap' initiatives. ${ }^{21}$ Although over half of the Indigenous population live in urban and regional centres, most research addresses the health and social issues of remote communities and only $11 \%$ of all articles about Indigenous health during a 5-year period addressed urban populations. ${ }^{21}$ However, preliminary data from our ongoing cohort study of ARI in young urban Indigenous children ${ }^{22}$ suggest $20 \%$ will develop chronic cough post-ARI, principally from PBB.

Early detection and appropriate management of the underlying aetiology (eg, bronchiectasis) causing chronic cough in children is important as it results in improved short ${ }^{23}$ and medium-term ${ }^{14}$ outcomes. Despite the availability of evidence-based cough management guidelines for children in several countries, ${ }^{24}{ }^{25}$ including Australia, ${ }^{26}$ the uptake and impact of the guidelines is largely unknown. So far, only one randomised controlled trial (RCT) has evaluated any of these guidelines $^{27} 28$ and economic evaluation was absent. This was conducted in five Australian cities where 272 children (mean age 4.5 years, SD 3.7) newly referred to a paediatric respiratory physician were randomly allocated to either early review and use of a cough algorithm or usual care until review and subsequent use of a predefined cough algorithm. ${ }^{27}{ }^{28}$ The study $^{28}$ found that children in the 'early-arm' group had significantly better clinical outcomes (ie, cough resolution at week 6 postintervention; absolute risk reduction $=24.7 \%, 95 \%$ CI $13 \%$ to $35 \%$ ) and better cough-specific QoL compared with the control group. However, in this study, ${ }^{28}$ the median duration of cough at enrolment was 16 weeks (IQR 832 ), and investigating earlier intervention is warranted. Furthermore, the use of the cough algorithm in 346 children found that $\sim 18 \%$ had a serious underlying illness. Indigenous children $(10 / 34 ; 29.4 \%)$ were more likely to have bronchiectasis than non-Indigenous children $(6.7 \% ; 21 / 312 ; \mathrm{OR}=5.78,95 \%$ CI 2.15 to 14.5 ; $\mathrm{p}<0.001) .^{29}$

Despite the high burden of ARI, there are little published data on interventions for acute and chronic cough, especially for urban and regional Indigenous children. An ARI sometimes unmasks a previously unrecognised chronic respiratory illness, which is a major problem in Indigenous Australians, but one that receives limited attention. ${ }^{30-32}$ Early diagnosis and management of chronic respiratory illness in children reduces morbidity and improves QoL. This RCT will therefore answer the primary question: 'Amongst children aged $<15$ years with chronic cough post-ARI, does active intervention at 4 weeks improve clinical outcomes?'

\section{Study objectives}

Our primary objective is to determine if children aged $<15$ years with chronic ( $>4$ weeks) cough post-ARI and managed according to an evidence-based cough 
algorithm have better clinical outcomes (faster cough resolution) than those receiving standard care.

Our secondary objectives are to:

1. Determine the cost-effectiveness of early intervention in chronic cough following an ARI compared to standard care.

2. Identify the microbiological predictors of chronic cough following an ARI.

3. Characterise the epidemiological, clinical, socioeconomic and cultural predictors of chronic cough following an ARI.

4. Establish the epidemiological, clinical, socioeconomic and cultural predictors of success or failure of an early intervention in chronic cough following an ARI.

Our study tests the primary hypothesis that among children aged $<15$ years with chronic ( $>4$ weeks) cough post-ARI, initiation of a cough management algorithm at the transition from acute to chronic cough will reduce cough duration.

\section{METHODS AND ANALYSIS \\ Study design}

A nested, open-label RCT (with concealed allocation) within a prospective cohort study of children aged $<15$ years presenting to three primary healthcare services with an ARI that includes cough as a symptom, and who are followed for 56 days (figure 1).

\section{Eligibility}

Inclusion criteria are:

- Aged $<15$ years,

- At the time of attending the clinic, the child is identified as having a possible respiratory illness (including those reported to have fever or viral/bacterial illness) that has parent-reported cough as a symptom,

- Provision of written informed consent from the parent/ guardian and assent from children aged $12-15$ years,
- Siblings are permitted if each meets the above criteria.

The exclusion criteria are: known diagnosis of an underlying medical condition, including chronic pulmonary disorders (excluding asthma); immunosuppressive illness, such as primary immunodeficiency, HIV infection or receiving immunomodulating drugs (except shortcourse ( $<2$ weeks) oral and ongoing maintenance inhaled corticosteroids) in the 30 days prior to presentation; current or planned participation in another intervention study during the 8 weeks of follow-up; severe ARI requiring hospitalisation, and/or insufficient English inhibiting provision of written informed consent or completion of participant interviews.

\section{Recruitment}

Eligible children are identified when presenting to one of three primary healthcare centres in subtropical, Southeast Queensland, Australia, involving metropolitan Brisbane (population 2.2 million), the regional city of Toowoomba (110000) and the rural town of Warwick (14 000). Parents and their child(ren) will be approached by clinic personnel and informed consent/assent obtained using written and/or pictorial plain language statements.

\section{Data collection, follow-up and intervention}

Children enrolled in each of the three primary healthcare centre cohorts undergo baseline clinical assessments that include demographic details, medical history, risk factors for ARI and cough, presenting features, vital signs, investigations, treatment and cost-of-illness data (figure 1). Weekly telephone and/or email and/or face-to-face contacts collect cough status, type (ie wet, dry variable) and cough score, ${ }^{33}$ medication (including over-the-counter remedies) and health service provider use for the cough and cost-of-illness data. Wet and dry cough are classified as per parent/carer reports, which
Figure 1 Overview of study design.

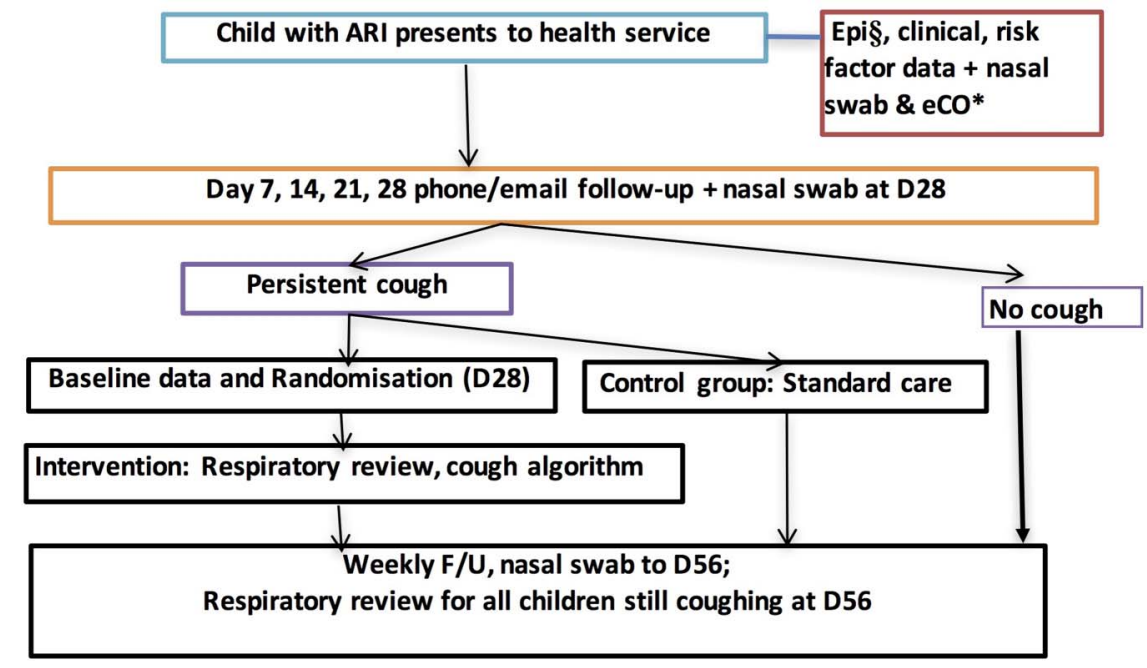

§Epidemiological * Exhaled carbon monoxide

ARI - acute respiratory illness; D28- Day 28; F/U - follow-up; D56 - Day 56 
were found previously to be accurate (compared with respiratory physician and bronchoscopy) in a study of children with chronic cough. ${ }^{34}$ The cost-of-illness data are collected at each parent/carer contact, specialist review and from examining medical records. A minimum of three contact attempts are made at each weekly time-point. We did not employ daily diary cards as planned originally, since although their use in chronic cough studies was reliable, we found that in children with acute cough diary completion and return rates were low during preliminary work undertaken for this study. We also could not use smartphone apps as the ownership of smart phones in the target communities is low. Thus, instead we relied on weekly parent recall of acute child illness, which has been shown to introduce minimal bias $(<10 \%)$ in prevalence studies. ${ }^{35}$

At day 28, any child with persistent cough (ie, $\leq 3$ day break in cough in the preceding 28 days) is randomised (1:1 allocation) to clinical review and initiation of the cough management algorithm or to continue weekly follow-up. All study participants continue weekly follow-up until day 56 and any child still coughing at that time point undergoes clinical review until a definitive diagnosis is established or the child exits the protocol. The decision to follow children until day 56 was based on data from our ED cough study, suggesting $42 \%$ of children with persistent cough at day 28 will be diagnosed with PBB (manuscript in preparation) that resolves with a 14-day course of amoxycillin-clavulanic acid. Children requiring ongoing care beyond two study physician reviews are referred to a tertiary paediatric respiratory medicine service.
The study intervention involves study physician clinical review within 2 weeks of day 28 where the cough management algorithm (figures 2 and 3) is implemented depending on whether the child has a specific or nonspecific cough. Children in whom the cough has resolved spontaneously between randomisation and physician review, and at that point are deemed by the study physician to require no further management, will not contribute to the primary analysis.

Children in the control group follow a standard care pathway. This reflects what occurs normally in the community for children with cough where the general waiting period for review by a paediatric respiratory physician is on average 6 weeks following referral from a family physician. The parents/guardians of children randomised to the control group are advised to continue follow-up with instructions that they will be reviewed by a study doctor following day 56 if they are still coughing. They are also counselled to seek advice from their family physician or other healthcare provider if their child becomes unwell or they are worried, otherwise to continue to self-manage their child's cough as they see fit.

\section{Randomisation, allocation and blinding}

An independent biostatistician prepared the randomisation code using a permuted blocking design (block size of 4) to maintain group balance. Randomisation was stratified by reason for presentation (ARI with cough or another reason with an ARI noted incidentally), site and cough duration at day 28 ( $<6$ or $\geq 6$ weeks). Group allocation is concealed in opaque, consecutively numbered
Figure 2 Specific cough pathway.
Specific cough pointers present or abnormal CXR or spirometry (if $>3-6$ years old)

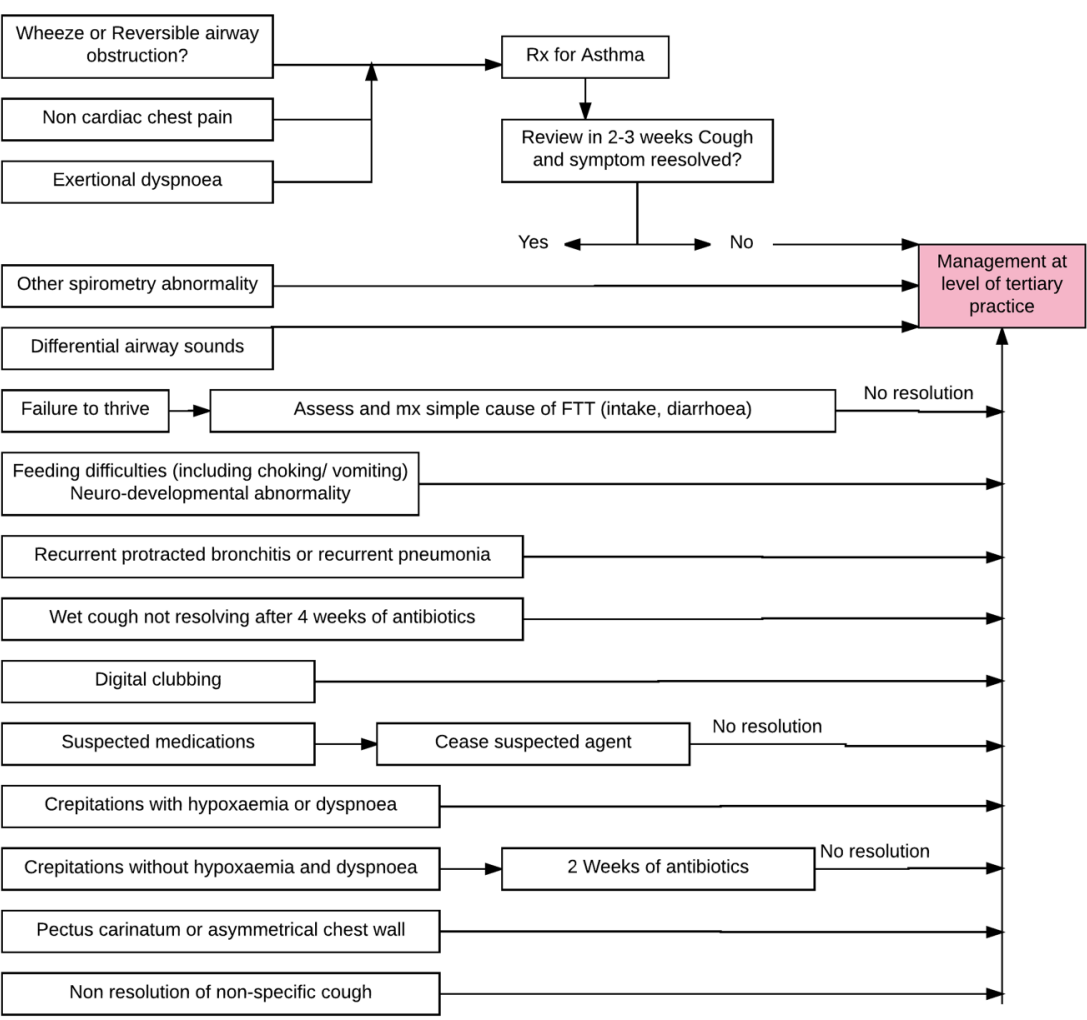


Figure 3 Non-specific cough pathway.

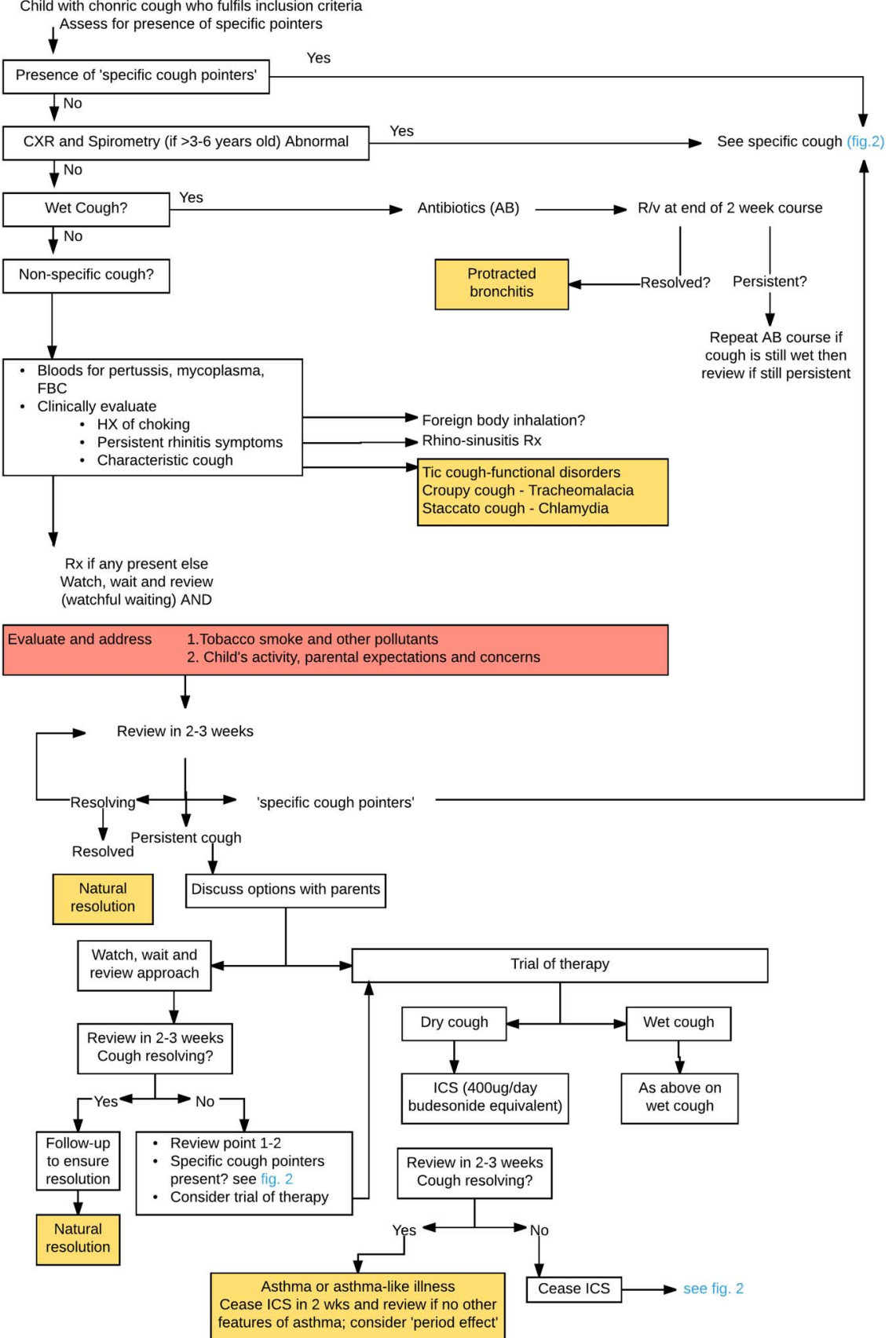

envelopes kept in a locked cabinet at the Centre for Children's Health Research, South Brisbane. At randomisation, the child's cough history over the past 28 days and study-specific strata are confirmed by the Central Coordinating Site. The Study Coordinator selects the next consecutively numbered, opaque, sealed envelope from the relevant strata pack, opens the envelope and extracts the randomisation code. Two people check the allocation and the code is assigned to the participant. The Study Coordinator then arranges for the study physician to review within 2 weeks of randomisation those children allocated to the intervention arm. If siblings are also enrolled and each child is still coughing at day 28, randomisation occurs for the first child enrolled (ie, earliest study number) and all siblings are allocated subsequently to the same arm. Differences in strata (eg presentation type and cough duration) will be accounted for in the analysis.

Blinding is not undertaken in this study; however, parents are not informed at enrolment that their child will be randomised at day 28 to a specific intervention if the child has a persistent cough. Instead, they are will be reviewed by a paediatrician during the study with some children being seen earlier and some later in the 8-week follow-up period. Limited disclosure is permitted under the Australian ethical standards for human research $^{36}$ if it is scientifically justifiable and does not present an increased risk of harm to the participant. informed that children who develop persistent cough 


\section{Definitions}

Definitions used for the clinical management pathway $^{2327}$ are as follows:

- Asthma: recurrent (>2) episodes of wheeze and/or dyspnoea that responds (within minutes) to inhaled $\beta_{2}$ agonist or demonstrates bronchodilator responsiveness documented on spirometry $(\geq 12 \%$ change in the percentage predicted forced expiratory volume in $1 \mathrm{~s}$ after $400 \mu \mathrm{g}$ of salbutamol).

- Cough resolution: improvement $\geq 75 \%$ or total resolution according to cough diary data for $\geq 3$ consecutive days. ${ }^{37}{ }^{38}$ When cough diary data are unavailable, resolution is defined as total cessation of cough according to parent/guardian verbal report.

- Chest radiograph abnormality: any abnormality (other than peribronchial thickening) identified by a paediatric respiratory physician or radiologist.

- Spirometry abnormality: as determined by the American Thoracic Society and European Respiratory Society criteria with Australian predicted values used. ${ }^{39}$

- Primary diagnosis of cough aetiology: diagnosis confirmed by subsequent specific treatment that resulted in cough resolution within 3 weeks. ${ }^{26} 37$ The diagnostic criteria are defined a priori following published guidelines: ${ }^{6}$

- PBB: presence of an isolated chronic wet or productive cough, without signs of another cause and which responds to at least a 2 weeks course of an appropriate antibiotic, such as amoxicillin-clavulanate.

- Recurrent PBB: $\geq 3$ episodes over a 12-month period.

- Reversible airway obstruction: in accordance with American Thoracic Society and European Respiratory Society criteria and adopting Australian predicted values. ${ }^{39}$

Secondary diagnosis: diagnosis found on objective tests, but where: (1) specific treatment did not lead to resolution or improvement in the cough; or (2) no treatment for this diagnosis was trialled and the cough either resolved spontaneously or with other therapies. ${ }^{6}$ Specific cough pointers: presence of any of the following: auscultatory abnormality (wheezes, crackles or differential breath sounds), classical cough characteristics, cardiac abnormalities, chest pain, chest wall deformity, daily moist or productive cough for $>3$ months, digital clubbing, dyspnoea (exertional or at rest), failure to thrive, feeding difficulties (including choking/vomiting), haemoptysis, immune deficiency, neuro-developmental abnormality, recurrent pneumonia and wheeze. These pointers are explained in the Thoracic Society of Australia and New Zealand position statement. ${ }^{37}$

Tertiary hospital management: that usually requires investigations to be conducted at a paediatric tertiary centre (eg, flexible bronchoscopy with bronchoalveolar lavage, chest high-resolution CT scan, fluoroscopic swallow screening, etc).

\section{Specimen collection}

At recruitment, exhaled carbon monoxide (eCO) measures from the child (if aged $\geq 3$ years and can provide an adequate sample) and parent/guardian are collected to provide an objective, non-invasive assessment of cigarette smoking status and exposure ${ }^{40}$ using a portable eCO monitor (Smokerlyzer, Bedfont Scientific, England).

All children have bilateral anterior nasal swabs collected at enrolment and at days 28 and 56. Anterior nasal swabs rather than nasopharyngeal swabs are being used as: (1) they are more acceptable to children; (2) in our experience have comparable sensitivity to nasopharyngeal specimens ${ }^{41}$ and, besides, any loss in sensitivity is considered acceptable when the purpose of the specimen is epidemiological rather than for a clinical diagno$\mathrm{sis}^{42}$ and (3) they permit more extensive swabbing of the nares. Nasal swabs are collected using Virocult plain cotton tip swabs with viral transport medium (Virocult, MW951, Medical Wire and Equipment, England) inserted $1 \mathrm{~cm}$ into the nostril and rotated four times on the right side and then on the left side. Swabs are stored locally in $-20^{\circ} \mathrm{C}$ freezers before being transported to the research laboratory where they are stored at $-80^{\circ} \mathrm{C}$ until processing occurs.

\section{Laboratory methods}

Swabs are batch-tested for respiratory viruses and bacteria using validated real-time PCR assays described previously. ${ }^{42}$ Virus testing includes rhinoviruses, adenovirus, respiratory syncytial virus, influenza virus types $\mathrm{A}$ and $\mathrm{B}$, parainfluenza virus types $1-3$, human metapneumovirus, human coronaviruses (OC43, 229E, NL63, HKU1), human bocavirus and human polyomaviruses KI and WU. Bacterial testing includes Bordetella pertussis, Mycoplasma pneumoniae, Streptococcus pneumoniae, Staphylococcus aureus, Haemophilus influenzae (including differentiating between encapsulated and non-encapsulated strains and Haemophilus haemolyticus) and Moraxella catarrhalis.

\section{End points}

Participation is completed 56 days $(+3$ days) following enrolment or, for children in the RCT, when a final diagnosis is determined by the study physician. Other exit points are serious protocol violations and worsening of the child's condition that requires hospitalisation or other active intervention elsewhere. Children meeting the exit criteria will continue to be followed until the end of the study period.

\section{Outcome measures}

Primary clinical outcome: Time-to-cough resolution in days. Secondary cost-effectiveness outcomes: Total direct and indirect costs of illness calculated according to the criteria outlined in table 1 .

Secondary microbiological outcomes: Anterior nasal detection by PCR of respiratory viruses and bacteria at days 28 and 56 . 
Table 1 Cost item, sector allocation and source of cost used in costing acute and chronic cough

\begin{tabular}{|c|c|c|}
\hline Cost item & Sector & Source of cost to be applied \\
\hline $\begin{array}{l}\text { Healthcare service usage } \\
\text { Includes costs for diagnostic tests and complementary/ } \\
\text { alternative therapies } \\
\text { Distinguishes between public and private, paid and } \\
\text { bulk-billed services }\end{array}$ & $\begin{array}{l}\text { Family } \\
\text { Healthcare } \\
\text { Health } \\
\text { insurers }\end{array}$ & $\begin{array}{l}\text { Manual of resource items and their } \\
\text { associated costs } \\
\text { National Hospital Costs Data Collection } \\
{ }^{45} \\
\text { Quarterly Gap Payment and Medical Benefits } \\
\text { Statistics } \\
\text { Medicare Quarterly Statistics } \\
\text { Medicare Benefits Schedule } \\
\text { Medi } \\
\text { Expert panel or large online provider where } \\
\text { required }\end{array}$ \\
\hline $\begin{array}{l}\text { Medication usage } \\
\text { Includes over-the-counter and prescribed medications } \\
\text { Healthcare seeking travel costs } \\
\text { Includes ambulance and community transport services }\end{array}$ & $\begin{array}{l}\text { Family } \\
\text { Healthcare } \\
\text { Family }\end{array}$ & $\begin{array}{l}\text { Pharmaceuticals Benefits Scheme (PBS) } \\
\text { Online providers when not listed on PBS } \\
\text { Parental Report } \\
\text { Private Health Insurance Administration } \\
\text { Council } \\
\text { Petrol: average unleaded retail price } \\
\text { Translink: average ticket prices }\end{array}$ \\
\hline $\begin{array}{l}\text { Time spent seeking healthcare } \\
\text { Time off work with pay } \\
\text { Time off work with pay lost } \\
\text { Time off usual activity }\end{array}$ & $\begin{array}{l}\text { Family } \\
\text { Employers }\end{array}$ & $\begin{array}{l}\text { Parental report } \\
\text { Average weekly earnings, Australia }{ }^{51}\end{array}$ \\
\hline $\begin{array}{l}\text { Extra time spent caring for child } \\
\text { Time off work with pay } \\
\text { - Time off work with pay lost } \\
\text { - Time off usual activity }\end{array}$ & $\begin{array}{l}\text { Family } \\
\text { Employers }\end{array}$ & $\begin{array}{l}\text { Parental report } \\
\text { Average weekly earnings, Australia }{ }^{51}\end{array}$ \\
\hline $\begin{array}{l}\text { Missed childcare/school } \\
\text { Missed planned activities } \\
\text { Child and others }\end{array}$ & $\begin{array}{l}\text { Family } \\
\text { Family }\end{array}$ & $\begin{array}{l}\text { Parental report } \\
\text { Parental report }\end{array}$ \\
\hline
\end{tabular}

\section{Sample size}

Sample sizes for each of the primary healthcare cohorts comprising this study are based on the expected number of eligible children with ARI presenting to each of these services over the study's timeframe and derived from our current studies of chronic cough post-ARI in children. ${ }^{22}{ }^{52}$ Between July 2015 and June 2017, we anticipate 750 eligible children will present to the primary healthcare services participating in this study.

Our preliminary data from a cohort study of Indigenous children aged $<5$ years $^{22}$ suggest $20 \%$ of Indigenous children with an ARI will have chronic cough at day 28. Based on data from the first study of the algorithm ${ }^{28}$ for the primary end point of cough resolution at day 56 , we anticipate a $54 \%$ reduction in the proportion of children $(54.3 \%$ in the early arm compared with $29.5 \%$ in the delayed arm) with persistent cough at day 56 . Hence, 89 children per group with complete evaluable data at day 56 will provide $90 \%$ power $(\alpha=0.05)$, to detect this $54 \%$ reduction for our primary aim. Assuming a $20 \%$ loss to follow-up and spontaneous resolution of cough of between randomisation and physician review of $5 \%$, we will therefore randomise a minimum of 112 children per group at day 28 across all 3 sites.

Given that the entire cohort study will have a 2-year recruitment period, and the natural history and predictors of chronic cough and cost-effectiveness of the intervention are important secondary outcomes, we will not limit recruitment to the RCT arm once 224 children have been randomised. Ongoing enrolment will hence increase study power to address the primary and secondary objectives. This approach has approval from the all relevant human research ethics committees (HREC).

\section{Data management}

Data will be entered into a password-protected, custombuilt, Filemaker Pro Advanced V.14 (Filemaker, Santa Clara, USA) database. The database has been designed to incorporate automatic data checking including logic and inaccurate ranges and maintains a $\log$ of any changes to the data. Data fields cannot be left blank and missing data must be coded as such in the database. A specific data management protocol compliant with the Queensland University of Technology's data management policies and principles is in place.

\section{Statistical methods}

Data will be presented in accordance with the updated CONSORT criteria. ${ }^{53}$ Demographic, clinical, economic, risk factor and microbiological data will be tabulated for the study population overall, by centre and by randomisation group and expressed as proportions and/or means of the selected characteristics by study centre, 
and presence/absence of chronic cough at day 56 with the corresponding 95\% CI. Differences between groups will be assessed using t-tests for comparisons of means and $\chi^{2}$ test for comparisons of proportions, conditional on test assumptions for each being satisfied. Non-normally distributed data will be analysed with appropriate non-parametric tests.

\section{Primary objective}

Intention-to-treat analyses will be employed. Timeto-cough resolution will be compared between groups using the Cox proportional hazard methods, adjusting for independent explanatory variables, subject to modelling assumptions being met, particularly proportionality of hazards. All analyses will be performed on the whole cohort and then additional analyses will be performed using frailty models ${ }^{54}$ that account for the clustering effects of siblings and site of recruitment.

\section{Economic objectives}

Costing of the intervention will be performed according to established methods, ${ }^{55}{ }^{56}$ including detailed subanalyses of data that account for epidemiological, social, cultural, risk factor and microbiological variables. Cost-effectiveness analysis (CEA) will be modelled using the health sector perspective. Broader societal issues using data from the trial as described above and augmented by the evidence from the literature, especially systematic reviews, will also be taken into consideration. The CEA approach will involve: identification of resources using the intervention pathway (activities, probabilities and unit costs); measurement of resource use/outcomes; and valuation of costs using unit costs published in the literature and from the trial itself. The time horizon will be specified and current practice (standard care) will be the comparator; and future costs and benefits will be discounted at $3 \%$ to present values. Central to this analysis will be the modelling of uncertainty surrounding data quality and gaps using sensitivity analyses, and extension of time horizon, using Treeage software (Treeage Software, Williamstown, Massachusetts, USA). The key outcomes will be incremental costeffectiveness, and cost-savings to the health system due to the interventions.

\section{Other objectives}

Multivariable modelling will be employed to: (1) evaluate the microbiological predictors of chronic cough following an ARI as determined at days 28, 42 and 56 postenrolment; (2) evaluate the epidemiological, clinical, socioeconomic and cultural predictors of chronic cough at day 28 post-ARI; (3) evaluate the epidemiological, clinical, socioeconomic and cultural predictors of success or failure of the intervention at day 56 and (4) to compare these predictors between the three study populations. Crude and adjusted relative risks and the respective $95 \%$ CIs will be presented, with differences considered statistically significant at $\mathrm{p}<0.05$.

Subgroup analyses will be performed for all primary and secondary objectives to examine potential differences by study-specific strata. Univariate and multivariate analyses will be performed to evaluate variables independently associated with study end points and to assess potential confounding factors in the association between vaccination and disease. Multiple imputation models will be used to evaluate the effect of missing data. Additional analyses will be undertaken to assess the effect of multiplicity in the assessment of microbial associations with cough outcomes.

\section{Participant safety}

Parents/guardians of all participants will be informed of any new information that arises during the study that may indicate potential harm to the child if he/she were to continue in the study. Any trial-related adverse events will be documented and reported to the relevant HREC. Serious adverse events will be reported to the HREC within 24 hours of notification and will be followed until resolution. A decision to withdraw the child following a serious adverse event will be made in consultation with the HREC, investigating team and the child's primary physician. If an adverse event is deemed related to study procedures, the child and his/her family will be eligible for compensation under the Clinical Trial Insurance policies in place for the duration of the study. All participant data will be kept confidential and stored securely in accordance with Australian Privacy Laws. Identifying data will not be provided to any persons outside of the study team unless required by Australian law (eg, in the event of the diagnosis of a notifiable disease). Published data will be deidentified and presented in aggregate form.

\section{Independent monitoring and quality control}

Independent study monitors have been engaged to undertake regular data quality audits, assess compliance with Good Clinical Practice guidelines and ensure that the study is being conducted according to the study protocol and ethical approvals. Inbuilt data quality monitoring and generation of data queries are established within the trial database, with data queries sent to study sites weekly for resolution.

\section{Protocol amendments}

All protocol amendments will be submitted to the study's HREC (see below) for approval prior to implementation. If any amendments have the potential to affect a family's willingness to continue in the study, all participants will be reconsented to the amended protocol.

\section{Study status}

Recruitment began in July 2015. 


\section{DISSEMINATION}

Participants will be provided with regular study progress reports and a written letter outlining the results of the study. The trial results, including any negative findings, will be published in open-access peer-reviewed journals and presented at scientific conferences, paediatric society and general practitioner meetings and other fora. The primary author of the main paper will be the principal investigator (KFO). The trial findings are likely to be incorporated into clinical management guidelines. Study data will be held in metadata repositories until the youngest child turns 25 years of age at the Queensland University of Technology. Deidentified study data will be made available to external parties on request and, if relevant, with the appropriate HREC approvals.

\section{DISCUSSION}

Chronic cough in children is a defining symptom of several chronic pulmonary disorders worldwide. Preventing persistent cough in children may lead to important short and long-term health benefits. Our proposed intervention ${ }^{22} 26$ is similar to the existing Australian guidelines, ${ }^{57}$ but also has some differences that were developed following the incorporation of new data unavailable at the time the guidelines were published. The use of guidelines by clinicians depends on several factors, which include level of evidence, feasibility, degree of implementation and inherent clinician factors. ${ }^{58}$ Using an algorithm facilitates clinical guideline implementation by clearly describing pathways of care based on whether the child presents with a specific or non-specific cough. While this study uses specific study physicians, the overall goal is widespread adoption of the guidelines and management algorithm in the primary healthcare setting. Our extensive data collection, including direct and indirect costs of illness and healthcare provision, are important in achieving this goal. The study will also provide an avenue for assessing the extent to which these guidelines are being used currently in different clinical settings given. We will collect data on any intervention a child may receive external to our study.

Study site selection was based on several factors, including existing relationships, feasibility and how they incorporated geographically and demographically different Indigenous communities. Studies evaluating ARI and chronic cough have had differing study designs, objectives and end points between populations. Australian data suggest cough burden is independent of age and aetiology, but dependent on clinical setting. ${ }^{29}$ In Australia, there are clear risk and burden distinctions between children from urban and remote areas and between Indigenous and non-Indigenous children. ${ }^{59}$ Indigenous children in urban areas have received much less attention than those in remote centres. Failure to account for these differences may lead to inappropriate interventions or implementation of management guidelines that may not be applicable across all settings.

The economic data and analyses in this study will be the first to describe the cost of ARI and its outcomes in Indigenous children in Australia, and one of the few worldwide. Further, the CEA of the intervention will provide data critical to clinical and public policy decisions with respect to incorporation of the intervention into routine care at the primary and tertiary healthcare levels. Such decisions will be enhanced by our incorporation of direct and indirect costs to the family, the community and the healthcare sector, ${ }^{60}$ particularly given the focus on resource allocation in Indigenous health in Australia, ${ }^{61}$ and the different mechanisms for delivery of primary healthcare services compared with mainstream Australia. ${ }^{62}$

We have incorporated microbiological components into the RCT as the role of infectious agents in the transition from ARI to chronic wet cough remains largely unknown. Whether persistent shedding, new acquisition and/or virus-bacteria interactions are associated with the development of chronic cough post-ARI is a clinical and research gap needing to be addressed. A study of 170 children aged 5-16 years presenting to their family physician with a cough lasting $>14$ days detected M. pneumoniae and B. pertussis in $12.9 \%$ and $36.6 \%$, respectively ${ }^{63}$ Cough duration was shorter in M. pneumoniae than $B$. pertussis cases and codetection with respiratory viruses was not associated with cough duration. ${ }^{63}$ An important limitation of this study ${ }^{63}$ was that data were not collected from the time of ARI onset. Other studies $^{64}$ have also tested for bacteria and viruses in nasopharyngeal specimens, but to date none have followed children from ARI onset and examined the association with developing chronic cough. In the analyses of microbiological data collected in our study of children attending an ED with cough, M. cattarhalis detected by PCR in anterior nasal swabs collected at time presentation was the only organism independently associated with persistent cough at 4 weeks after controlling for age, gender and the presence of any viruses. ${ }^{5}$ Our Brisbane-based lower airway studies of children with chronic cough from PBB found intense neutrophilic airway inflammation and evidence of innate immune activation, suggesting that PBB may follow a single ARI episode with impaired pathogen clearance from the airways, either permanently or temporarily leading to a cycle of chronic inflammation. ${ }^{65}$ Small case series from the late 1990s have reported chronic pulmonary sequelae following influenza infection in young children ${ }^{66}$ and a relationship between adenovirus infection and bronchiectasis. ${ }^{67}$

The major threats to the validity of our proposal are loss to follow-up and potential for contamination of the control group based on the type of standard care they may receive. In our current ARI study in urban Indigenous children, loss to follow-up at the 4-week time point post-ARI is $23 \%$. Procedures to minimise this loss 
include: home visiting by Indigenous research personnel, regular text and email messaging, and personal letters to families. Analysis plans will include measures to account for missing data and sensitivity analyses to assess the extent of bias.

Although contamination of the control group is possible, based on a multicentre RCT conducted in five major Australian cities, ${ }^{29}$ it is unlikely that a child in standard care will receive treatment similar to the intervention arm. In another of our studies, ${ }^{52}$ just $27 \%$ of children sought further medical advice for cough in the 4 weeks following presentation to an ED for an illness with cough as a symptom (unpublished data). Furthermore, of the $9.7 \%$ receiving antibiotics during this 4 -week period, ${ }^{5}$ most were prescribed antibiotics at the time of the original ED presentation. Hence, it is unlikely this will influence the validity of our RCT for several reasons: (1) We can assess any intervention either group receives outside of the RCT since our weekly follow-up data collection captures these events. (2) In the possible, but unlikely event of a change in treatment in the control group, the effect size of the intervention will be smaller requiring a larger sample size. The a priori sample size is conservative with $90 \%$ power and a smaller effect size will still be detectable within the available study population (eg, a $35 \%$ difference with power of $80 \%$ requires 114 per group). (3) To ensure robustness, an independent person will recalculate the sample size when $50 \%$ of children have completed the RCT component.

In summary, our RCT will be the first to examine the impact of a cough management algorithm implemented at the transitional stage from acute to chronic cough in Indigenous children. Clinical effectiveness will be evaluated concurrently with detailed epidemiological, clinical, microbiological and economic determinants of ARI and cough persistence in this population. If successful, the study may provide the data necessary to facilitate the uptake and implementation of cough management guidelines in the primary healthcare setting, potentially reducing the long-term burden of disease on the child, family, community and healthcare sector.

\footnotetext{
Author affiliations

${ }^{1}$ Centre for Children's Health Research, Institute of Health and Biomedical Innovation, Queensland University of Technology, Brisbane, Queensland, Australia

${ }^{2}$ Menzies Health Institute Queensland, Griffith University and Gold Coast Health, Southport, Queensland, Australia

${ }^{3}$ The University of Queensland Rural Clinical School, The University of Queensland, Toowoomba, Queensland, Australia

${ }^{4}$ Carbal Health Services, Toowoomba, Queensland, Australia

${ }^{5}$ Menzies School of Health Research, Charles Darwin University, Casuarina, Northern Territory, Australia

${ }^{6}$ Queensland Paediatric Infectious Diseases Laboratory, Children's Health Queensland, Brisbane, Queensland, Australia

${ }^{7}$ Faculty of Medicine and Biomedical Sciences, The University of Queensland, Herston, Queensland, Australia

${ }^{8}$ School of Public Health, Australian Catholic University, Sydney, New South Wales, Australia
}

${ }^{9}$ Caboolture Community Medical, Caboolture, Queensland, Australia

${ }^{10}$ School of Medicine, The University of Sydney, Newtown, New South Wales, Australia

${ }^{11}$ Wesley Medical Centre, Brisbane, Queensland, Australia

${ }^{12}$ Ferny Grove Chambers Medical Practice, Brisbane, Queensland, Australia

${ }^{13}$ Department of Paediatrics, Toowoomba Hospital, Toowoomba, Queensland, Australia

${ }^{14}$ Queensland Children's Respiratory Centre, Lady Cilento Children's Hospital, Brisbane, Queensland, Australia

Acknowledgements The authors thank those who have facilitated the study Robert Ware for generating the randomisation sequences; Daniel Arnold for database development and data management; the Boards and staff of Murri Medical and Carbal Health Services and the Respiratory infection Outreach and Research Team's Indigenous Research Reference Group for their cultural oversight and support of the study. This project is conducted under the auspices of the NHMRC Centre for Research Excellence in Lung Health for Aboriginal and Torres Strait Islander children (1040830).

Contributors KFO conceived the study, devised the study protocol and oversees study implementation nationally and was the primary author of the manuscript. KG contributed to study conception, the grant application and will play a leading role in the interpretation of the microbiological data. MT contributed to study conception, grant application, community consultation and implementation of the study. TPS and DW contributed to study conception and the grant application and are responsible for the microbiological components of the study and interpretation of the laboratory data. MO contributed to study conception and the grant application and is responsible for the economic components of the study. $\mathrm{SR}$ is the National Study Coordinator with major input into data instruments, standard operating procedures and GCP compliance. HB, AC, $\mathrm{DA}$ and $\mathrm{OMk}$ are responsible for the clinical implementation of the intervention and evaluation of study diagnostic outcomes. PJT contributed to study conception and will play a role in knowledge translation and implementation of study findings into clinical guidelines. $A B C$ played a major role in study conception, grant application, protocol development and implementation and helped draft the manuscript. All authors read and approved the final manuscript.

Funding The study is funded by a 3-year Australian National Health and Medical Research Council (NHMRC) project grant (1080298). KFO is supported by an NHMRC Career Development Fellowship (1045157). ABC (grant 545216) is supported by an NHMRC practitioner fellowship.

Competing interests None declared.

Patient consent Obtained.

Ethics approval Queensland Children's Health Services Human Research Ethics Committee and the Queensland University of Technology University Research Ethics Committee.

Provenance and peer review Not commissioned; externally peer reviewed.

Open Access This is an Open Access article distributed in accordance with the Creative Commons Attribution Non Commercial (CC BY-NC 4.0) license, which permits others to distribute, remix, adapt, build upon this work noncommercially, and license their derivative works on different terms, provided the original work is properly cited and the use is non-commercial. See: http:// creativecommons.org/licenses/by-nc/4.0/

\section{REFERENCES}

1. Britt $\mathrm{H}$, Miller GC, Charles J, et al. General practice activity in Australia 2009-10. General Practice Series no. 27. Canberra: AIHW, 2010.

2. Irwin RS, Gutterman DD. American College of Chest Physicians cough guidelines. Lancet 2006;367:981.

3. Whitburn S, Costelloe C, Montgomery AA, et al. The frequency distribution of presenting symptoms in children aged six months to six years to primary care. Prim Health Care Res Dev 2011;12:123-34.

4. Chang AB. Cough: are children really different to adults? Cough 2005;1:7. 
5. O'Grady KF, Grimwood K, Sloots TP, et al. Upper airway viruses and bacteria and clinical outcomes in children with cough. Pediatr Pulmonol. doi: 10.1002/ppul.23527 [Epub ahead of print] 26 Jul 2016

6. Marchant JM, Masters IB, Taylor SM, et al. Evaluation and outcome of young children with chronic cough. Chest 2006;129:1132-41.

7. Marchant JM, Newcombe PA, Juniper EF, et al. What is the burden of chronic cough for families? Chest 2008;134:303-9.

8. Thompson M, Vodicka TA, Blair PS, et al. Duration of symptoms of respiratory tract infections in children: systematic review. BMJ 2013;347:f7027.

9. Hay $A D$, Wilson $A D$. The natural history of acute cough in children aged 0 to 4 years in primary care: a systematic review. $\mathrm{Br} J$ Gen Pract 2002:52:401-9.

10. Chang AB, Faoagali J, Cox NC, et al. A bronchoscopic scoring system for airway secretions-airway cellularity and microbiological validation. Pediatr Pulmonol 2006;41: 887-92.

11. Douros K, Alexopoulou E, Nicopoulou A, et al. Bronchoscopic and high-resolution CT scan findings in children with chronic wet cough. Chest 2011;140:317-23

12. Chang AB, Redding GJ, Everard ML. Chronic wet cough: protracted bronchitis, chronic suppurative lung disease and bronchiectasis. Pediatr Pulmonol 2008;43:519-31.

13. Bastardo CM, Sonnappa S, Stanojevic S, et al. Non-cystic fibrosis bronchiectasis in childhood: longitudinal growth and lung function. Thorax 2009;64:246-51.

14. Kapur N, Masters IB, Chang AB. Longitudinal growth and lung function in pediatric non-cystic fibrosis bronchiectasis: what influences lung function stability? Chest 2010;138:158-64.

15. Pink B, Allbon P. The health and welfare of Australia's aboriginal and Torres Strait Islander peoples: 2008. Canberra: Australian Bureau of Statistics and Australian Institute of Health \& Welfare, 2008.

16. O'Grady KA, Taylor-Thomson DM, Chang AB, et al. Rates of radiologically confirmed pneumonia as defined by the World Health Organization in Northern Territory Indigenous children. Med $J$ Aust 2010;192:592-5.

17. O'Grady KA, Torzillo PJ, Chang AB. Hospitalisation of Indigenous children in the Northern Territory for lower respiratory illness in the first year of life. Med J Aust 2010;192:586-90.

18. Chang AB, Grimwood K, Mulholland EK, et al. Bronchiectasis in indigenous children in remote Australian communities. Med $J$ Aust 2002;177:200-4.

19. Valery PC, Torzillo PJ, Mulholland K, et al. Hospital-based case-control study of bronchiectasis in indigenous children in Central Australia. Pediatr Infect Dis J 2004;23:902-8.

20. Singleton RJ, Valery PC, Morris P, et al. Indigenous children from three countries with non-cystic fibrosis chronic suppurative lung disease/bronchiectasis. Pediatr Pulmonol 2014;49:189-200.

21. Eades SJ, Taylor B, Bailey S, et al. The health of urban Aboriginal people: insufficient data to close the gap. Med J Aust 2010;193:521-4.

22. Hall KK, Chang AB, Sloots TP, et al. The respiratory health of urban indigenous children aged less than 5 years: study protocol for a prospective cohort study. BMC Pediatr 2015;15:56

23. Chang $A B$, Robertson $C F$, van Asperen PP, et al. A cough algorithm for chronic cough in children: a multicenter, randomized controlled study. Pediatrics 2013;131:e1576-83.

24. Irwin RS, Baumann MH, Bolser DC, et al. Diagnosis and management of cough executive summary: ACCP evidence-based clinical practice guidelines. Chest 2006;129 (1 Suppl):1S-23S.

25. Keeley D. Cough in children: new guidelines from the British Thoracic Society. Postgrad Med J 2008;84:449.

26. Chang AB, Glomb WB. Guidelines for evaluating chronic cough in pediatrics: ACCP evidence-based clinical practice guidelines. Chest 2006;129(1 Suppl):260S-83S.

27. Chang $A B$, Robertson $C F$, van Asperen PP, et al. Can a management pathway for chronic cough in children improve clinical outcomes: protocol for a multicentre evaluation. Trials 2010;11:103

28. Chang AB, Robertson CFPP, van Asperen PP, et al. Effect of a cough algorithm on chronic cough in children: a multicentre randomized controlled study. Pediatrics 2013;131:e1576-83.

29. Chang AB, Robertson CF, Van APP, et al. A multi-centre study on chronic cough in children: burden and etiologies based on a standardized management pathway. Chest 2012;142:943-50.
30. O'Grady KA, Revell A, Maguire GP, et al. Lung health care for Aboriginal and Torres Strait Islander Queenslanders: breathing easy is not so easy. Aust Health Rev 2011;35:512-19.

31. O'Grady KF, Revell A, Maguire G, et al. Lung health services for aboriginal and Torres Strait Islander peoples in Queensland. Brisbane: Queensland Government, 2010.

32. Chang AB, Marsh RL, Upham JW, et al. Toward making inroads in reducing the disparity of lung health in Australian indigenous and New Zealand Maori children. Front Pediatr 2015;3:9.

33. Chang AB, Newman RG, Carlin JB, et al. Subjective scoring of cough in children: parent-completed vs child-completed diary cards vs an objective method. Eur Respir J 1998;11:462-6.

34. Chang AB, Gaffney JT, Eastburn MM, et al. Cough quality in children: a comparison of subjective vs. bronchoscopic findings. Respir Res 2005;6:3.

35. Arnold BF, Galiani S, Ram PK, et al. Optimal recall period for caregiver-reported illness in risk factor and intervention studies: a multicountry study. Am J Epidemiol 2013;177:361-70.

36. Council NHMR. National statement on ethical conduct in human research (2007). Canberra: Australian Government, 2007.

37. Chang $\mathrm{AB}$, Landau $\mathrm{LI}$, Van Asperen PP, et al. Cough in children: definitions and clinical evaluation-position statement of the Thoracic Society of Australia and New Zealand. Med J Aust 2006;184:398-403.

38. Marchant JM, Masters IB, Taylor SM, et al. Utility of signs and symptoms of chronic cough in predicting specific cause in children Thorax 2006;61:694-8.

39. Hibbert ME, Lannigan A, Landau $\mathrm{LI}$, et al. Lung function values from a longitudinal study of healthy children and adolescents. Pediatr Pulmonol 1989;7:101-9.

40. Sandberg A, Skold CM, Grunewald J, et al. Assessing recent smoking status by measuring exhaled carbon monoxide levels. PLOS ONE 2011;6:e28864.

41. Lambert SB, Whiley DM, O'Neill NT, et al. Comparing nose-throat swabs and nasopharyngeal aspirates collected from children with symptoms for respiratory virus identification using real-time polymerase chain reaction. Pediatrics 2008;122: e615-20.

42. O'Grady KA, Torzillo PJ, Rockett RJ, et al. Successful application of a simple specimen transport method for the conduct of respiratory virus surveillance in remote Indigenous communities in Australia. Trop Med Int Health 2011;16:766-72.

43. O'Grady KA, Whiley DM, Torzillo PJ, et al. Mailed versus frozen transport of nasal swabs for surveillance of respiratory bacteria in remote Indigenous communities in Australia. BMC Infect Dis 2013;13:543.

44. Department of Health \& Ageing. Manual of resource items and their associated costs for use in submissions to the Pharmaceutical Benefits Advisory Committee involving economic evaluation. Canberra: Australian Government, 2015 (cited 1 April 2015). http:// www.health.gov.au/internet/main/publishing.nsf/content/ health-pbs-general-pubs-manual-content.htm

45. Department of Health and Ageing. National Hospital Cost Data Collection (NHCDC) Report. Canberra: Australian Government. http://www.health.gov.au/internet/main/publishing.nsf/content/ health-casemix-data-collections-NHCDCReports

46. Private Health Insurance Administration Council. Quarterly gap payment \& medical benefits statistics. Canberra: Australian Government, 2012. http://phiac.gov.au/wp-content/uploads/2012/11/ Gap-Sep12.pdf

47. Department of Health \& Ageing. Quarterly medicare statistics. Canberra: Australian Government. http://www.health.gov.au/internet/ main/publishing.nsf/Content/Quarterly-Medicare-Statistics

48. Department of Health \& Ageing. Medicare benefits schedule. Canberra: Australian Government. http://www.mbsonline.gov.au/

49. Department of Health and Ageing Pharmaceutical Benefits Scheme. Canberra: Australian Government . http://www.pbs.gov.au/pbs

50. Private Health Insurance Administration Council. Private Health Insurance Administration Council Queensland Reports. Canberra: Australian Government. http://phiac.gov.au/industry/ industry-statistics

51. Australian Bureau of Statistics. Average weekly earnings. Canberra, Australia: Australian Government. http://www.abs.gov.au/austats

52. Drescher BJ, Chang AB, Phillips N, et al. The development of chronic cough in children following presentation to a tertiary paediatric emergency department with acute respiratory illness: study protocol for a prospective cohort study. BMC Pediatr 2013;13:125.

53. Schulz KF, Altman DG, Moher D. CONSORT 2010 Statement: updated guidelines for reporting parallel group randomised trials. Trials 2010;11:32. 
54. Hougaard P. Frailty models for survival data. Lifetime Data Anal 1995;1:255-73.

55. Drummond MF, Sculpher MJ, Torrance GW. Methods for the economic evaluation of health care programs. Oxford: Oxford University Press, 2005.

56. Gold MR, ed. Cost effectiveness in health and medicine. Oxford: Oxford University Press, 1996.

57. Gibson PG, Chang AB, Glasgow NJ, et al. CICADA: Cough in Children and Adults: Diagnosis and Assessment. Australian cough guidelines summary statement. Med J Aust 2010;192:265-71.

58. Chang $A B$, Landau LI, Van Asperen PP, et al. Cough in children: definitions and clinical evaluation. Med J Aust 2006;184:398-403.

59. O'Grady KA, Chang AB. Lower respiratory infections in Australian Indigenous children. J Paediatr Child Health 2010;46:461-5.

60. Ungar WJ, Coyte PC, Pharmacy Medication Monitoring Program Advisory Board. Prospective study of the patient-level cost of asthma care in children. Pediatr Pulmonol 2001;32:101-8.

61. Peiris D, Brown A, Howard M, et al. Building better systems of care for Aboriginal and Torres Strait Islander people: findings from the
Kanyini health systems assessment. BMC Health Serv Res 2012;12:369.

62. Ong KS, Carter R, Kelaher M, et al. Differences in primary health care delivery to Australia's Indigenous population: a template for use in economic evaluations. BMC Health Serv Res 2012:12:307.

63. Wang K, Chalker V, Bermingham A, et al. Mycoplasma pneumoniae and respiratory virus infections in children with persistent cough in England: a retrospective analysis. Pediatr Infect Dis J 2011;30:1047-51.

64. Bisgaard $\mathrm{H}$, Hermansen MN, Bonnelykke $\mathrm{K}$, et al. Association of bacteria and viruses with wheezy episodes in young children: prospective birth cohort study. BMJ 2010;341:c4978.

65. Marchant JM, Gibson PG, Grissell TV, et al. Prospective assessment of protracted bacterial bronchitis: airway inflammation and innate immune activation. Pediatr Pulmonol 2008;43:1092-9.

66. Laraya-Cuasay LR, DeForest A, Huff D, et al. Chronic pulmonary complications of early influenza virus infection in children. Am Rev Respir Dis 1977;116:617-25.

67. Bateman ED, Hayashi S, Kuwano K, et al. Latent adenoviral infection in follicular bronchiectasis. Am J Respir Crit Care Med 1995;151:170-6. 